\title{
LEFT AURICULAR ENLARGEMENT IN ENDOCARDIAL FIBRO-ELASTOSIS
}

\author{
BY \\ J. L. FREER and W. J. MATHESON \\ From the Radiological Department and Children's Hospital, Leicester Roval Infirmary.
}

(RECEIVED FOR PUBLICATHON APRIL 27, 1953)

Endocardial fibro-elastosis or endocardial sclerosis, a disease in which the endocardium, mainly of the left side of the heart, is greatly thickened with fibrous and elastic tissue, is now being more frequently recognized. In 1946 Cosgrove and Kaump collected 44 cases from the literature and added six of their own. Since then at least an equal number of cases has been reported, including a description of 25 by Blumberg and Lyon (1952) collected over a period of five years.

The majority of cases occur in infancy: they present with signs of heart failure either of sudden onset and rapidly fatal, or running a more prolonged course fluctuating in severity but in the end also causing death. The other outstanding clinical feature is cardiac enlargement, usually gross and usually unaccompanied by cardiac murmurs.

A presumptive diagnosis can certainly be made on clinical grounds alone, but we have found that the radiological demonstration of left auricular enlargement is a useful confirmatory sign.

\section{Case Reports}

Case 1. A girl aged 6 years was admitted to hospital in cardiac failure. On examination the heart was grossly enlarged: there was a faint apical systolic murmur. Radiographs showed marked cardiac enlargement, mainly of the left auricle and ventricle. Thought to be suffering from acute rheumatism, she improved for a time with salicylates and digitalis but died suddenly a week after admission. Post-mortem examination confirmed the cardiac enlargement mainly affecting the left side; the endocardium was not considered to be abnormal macroscopically but sections showed marked endocardial thickening.

Case 2. A girl aged 2 years was admitted to hospital in cardiac failure. On examination the heart was greatly enlarged. Radiographs showed left auricular enlargement (Fig. 1 and Table 1). Although she improved initially, there was persistent tachycardia with apical triple rhythm, heart failure recurred, and she died two months after admission. Necropsy confirmed the cardiac enlargement affecting mainly the left auricle and ventricle (Fig. 2): the endocardium was white and thickened on section and this thickening was shown to be mainly due to an increase in elastic fibres (Fig. 3).

Case 3. A girl aged 3 years was admitted because of abdominal distension of one month's duration and

TABLE 1

SUMMARY OF CARDIAC AND PULMONARY CHANGES IN PRESENT SERIES

\begin{tabular}{|c|c|c|c|c|}
\hline Case No. & $\begin{array}{c}\text { Cardiac } \\
\text { Enlargement }\end{array}$ & $\begin{array}{l}\text { L. Auricle } \\
\text { (P.A. View) }\end{array}$ & $\begin{array}{c}\text { L. Auricle } \\
\text { (R.A.O.) }\end{array}$ & $\begin{array}{c}\text { Pulmonary } \\
\text { Changes }\end{array}$ \\
\hline 1 & $-\cdots$ & 0 & $-\cdots$ & - \\
\hline 2 & $-\cdots$ & -- & --- & - \\
\hline 3 & $-\cdots$ & $\ldots$ & $\underset{\text { not }}{\text { obtained }}$ & -- \\
\hline 4 & -- & - & - & - \\
\hline 5 & -- & 0 & -- & -- \\
\hline 6 & $-\div$ & - & $-\cdots$ & --- \\
\hline 7 & -- & 0 & -- & --- \\
\hline
\end{tabular}

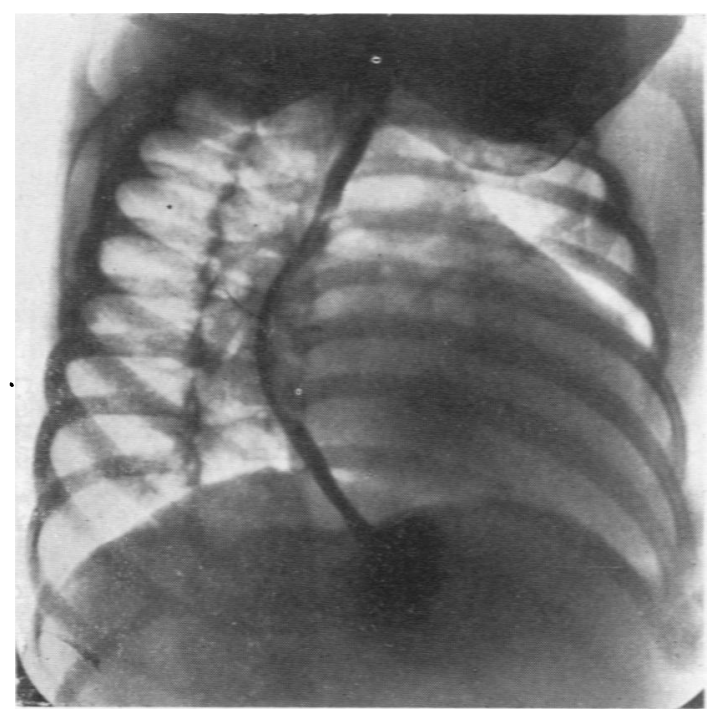

FIG. 1.-Case 2. R.A.O. view showing left auricular enlargement. 


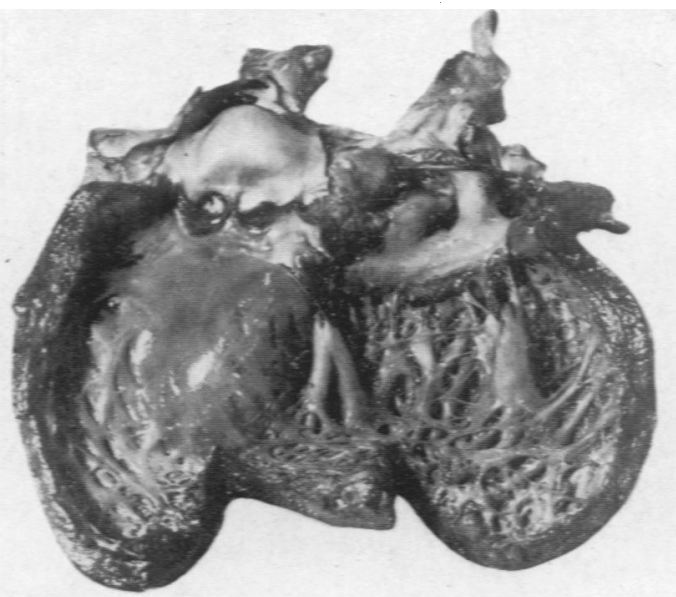

Fig. 2-Case 2: heart showing left ventricle which is much enlarged; towards the apex the endocardium is white and thickened.

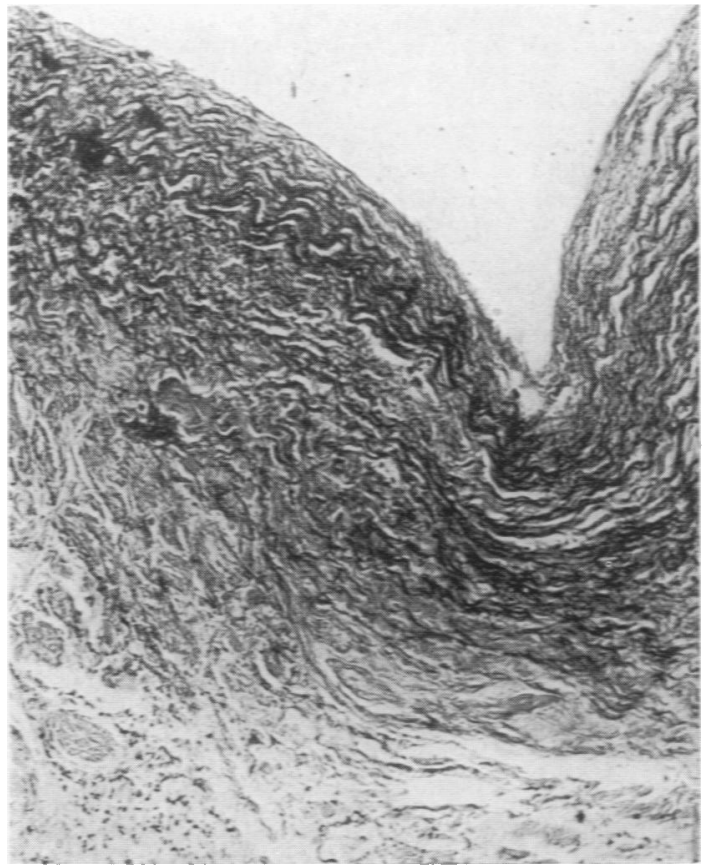

Fig. 3.-Case 2.-Section of left auricle (Weigert's chastin stain $\times 210$ ) showing thickening of endocardium and great increase of elastic tissue.

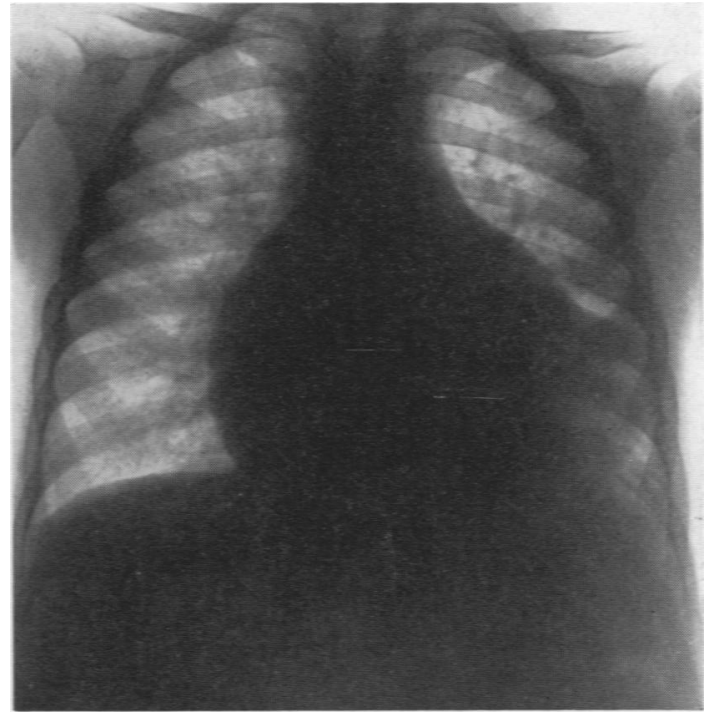

Fig. 4.-Case 3. P.A. view showing left auricular shadow within the cardiac shadow.

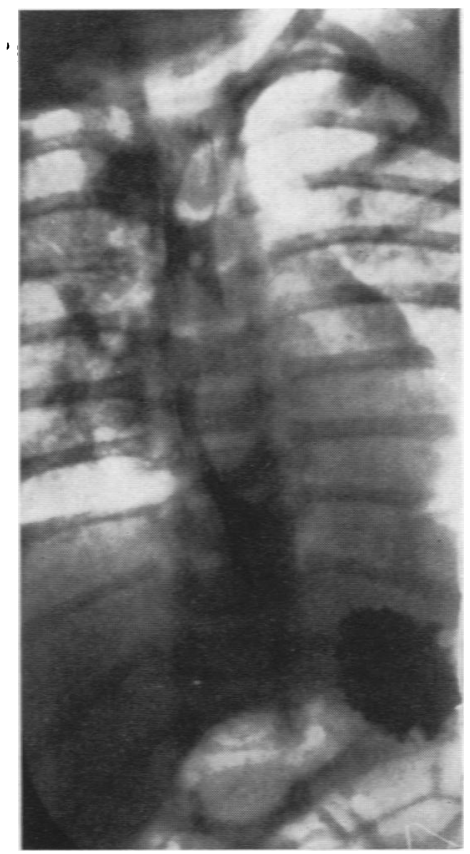

Fig. 5.-Case 4. P.A. view showing oesophageal displacement to the right. 
swelling of the legs and eyelids for one week. She was thought to have a primary abdominal sarcoma with extension to the mediastinum. Radiographs, however, showed marked cardiac enlargement and enlargement of the left auricle in the postero-anterior view (Fig. 4 and Table 1). There was persistent dyspnoea and tachycardia and she died after a month in hospital. Post-mortem examination showed gross dilatation of the left auricle and ventricle; the endocardium was thickened and the liver cirrhotic.

Case 4. A girl was aged 14 months on first admission to hospital because of wheezing, difficulty in swallowing solids, and abdominal enlargement of four months' duration. Physical examination showed enlargement of the liver, spleen and lymph nodes. She was thought to be suffering from a form of reticulosis and was discharged after one month in hospital, her symptoms having disappeared. Readmitted a month later, she was obviously in cardiac failure which persisted despite digitalization. Terminally she developed a pleural effusion. Radiographs showed cardiac enlargement with displacement of the barium-filled oesophagus to the right in the postero-anterior view (Fig. 5 and Table 1). Necropsy confirmed the cardiac enlargement mainly affecting the left side: the endocardium was thickened and there was a mild degree of mitral stenosis. Histological examination showed that the endocardial thickening was due mainly to a great increase in elastic fibres (Fig. 6).

Case 5. A girl was aged 2 weeks when first seen because of cyanotic attacks. The heart was enlarged and she was in cardiac failure. She improved for a time with digitalis although the cyanotic attacks continued, but died at the age of 8 weeks. Radiographs showed gross cardiac enlargement with marked enlargement of the left auricle

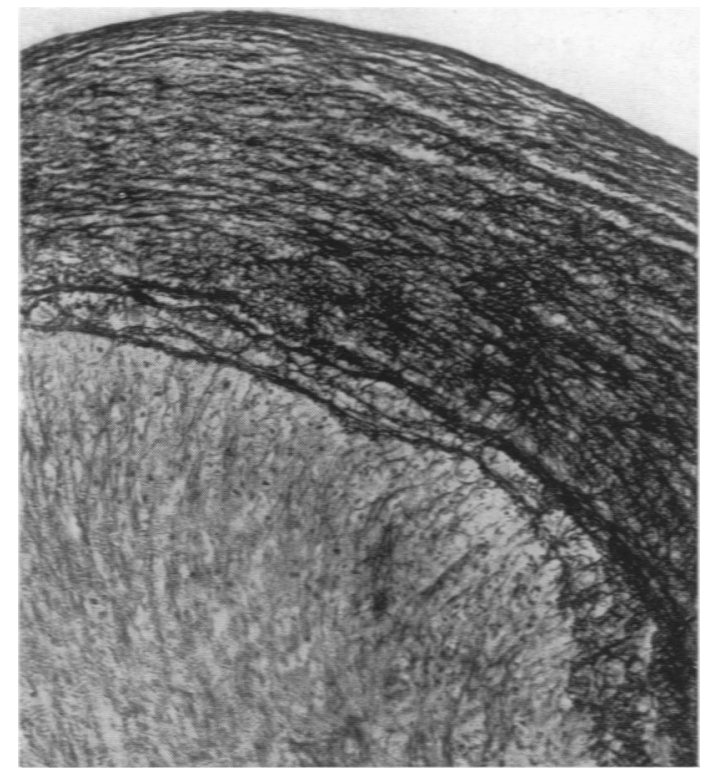

FiG. 6.-Case 4: section of left auricle (Weigert's elastin stain $\times 90$ ) showing the increase of elastic tissue in the endocardium.

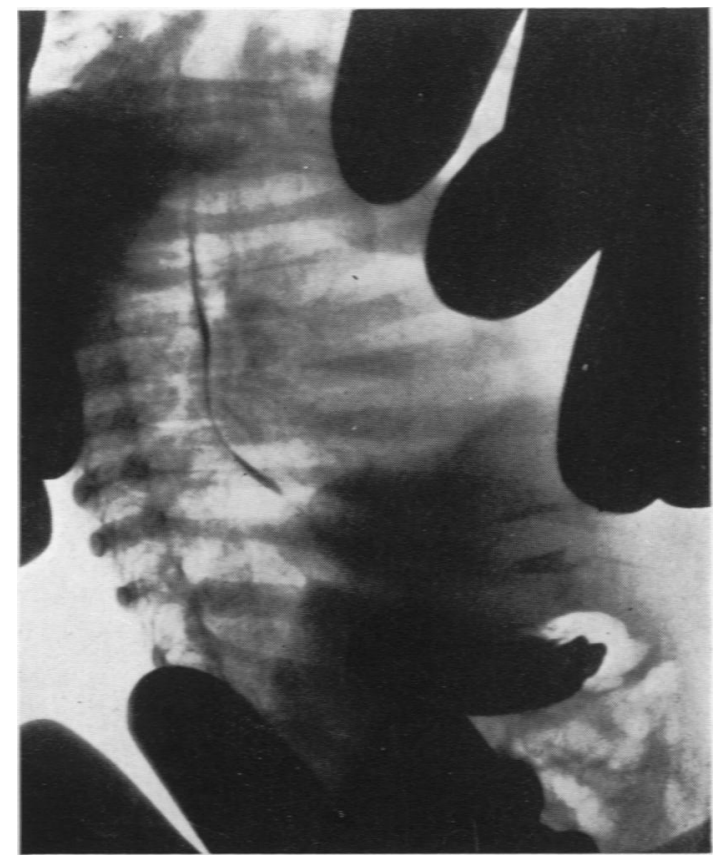

Fig. 7.-Case 6. R.A.O. view showing left auricular enlargement

(Table 1). Post-mortem examination confirmed the $ᄋ$ of cardiac enlargement: only the endocardium of the left auricle was thickened.

Case 6. A girl was aged 14 months on first admission to hospital. The history was of intermittent pyrexia and changing signs in the chest for the past month. The heart was grossly enlarged, there were signs of infarction at the right lung base, and the child was in cardiac failure. There was rapid improvement with digitalis and she was discharged after one month in hospital. Radiographs showed marked cardiac enlargement and marked enlargement of the left auricle (Fig. 7 and Table 1). She was readmitted a month later with signs of pulmonary infarction which soon cleared, and again six weeks afterwards when she died of cardiac failure a few hours after admission. At necropsy the heart was greatly enlarged, especially the left side where the endocardium was white and thickened.

Case 7. A girl, aged 9 months, was admitted in cardiac failure with a grossly enlarged heart and apical systolic and diastolic murmurs. She did not respond to treatment and died six days after admission. Radiographs showed left auricular enlargement (Table 1). Post-mortem examination showed a large left auricle and left ventricle: there was severe mitral stenosis, the aortic cusps were thickened, and the endocardium was opaque and thickened.

\section{Discussion}

Our attention was first drawn to the usefulness oi left auricular enlargement as a diagnostic sign when it enabled us to make a retrospective diagnosis in Case 1; here the finding of left auricular enlargement 
was unexpected clinically and unexplained at necropsy. When, however, this sign was found also in Case 2 in which a presumptive diagnosis of endocardial fibro-elastosis had been made during life and when this diagnosis was proved at necropsy, the sections of Case 1 were re-examined and the endocardial thickening was then plainly seen. It may be remarked here that the endocardium, classically described as being opaque, white, and glistening, may not appear convincingly abnormal macroscopically at necropsy and sections may be needed to demonstrate the endocardial thickening.

The diagnosis of left auricular enlargement has been based on evidence of backward displacement of the barium-filled oesophagus in the right anterior oblique position, the presence of a dense left auricular shadow within the cardiac shadow in the postero-anterior view and deviation of the bariumfilled oesophagus to the right in the postero-anterior position. Fluoroscopy was carried out in six patients, definite left auricular enlargement being present in five (Cases 1, 2, 5, 6, 7); in the other case (Case 4), this enlargement was minimal but additional evidence of it was shown by cesophageal displacement to the right in the postero-anterior view. Radiographs in the right antero-oblique position were obtained in five patients (Cases 2, 4, $5,6,7)$ and confirmed the appearances seen on fluoroscopy. An enlarged left auricular shadow was thought to be demonstrated in the postero-anterior view in two patients (Cases 2 and 3 ) and in the one case (Case 3) without fluoroscopy or oblique view this was a marked feature.

The other radiological features consisted of cardiac enlargement and pulmonary changes. There was obvious cardiac enlargement in the erect posteroanterior views in every case and the enlargement was considered to be mainly left sided. As regards the pulmonary changes, hyperaemia was present in varying degree in all cases. In two (Cases 4 and 6) there was a suspicion of infarction; Case 4 developed a pleural effusion terminally.

Radiologically the outstanding feature of endocardial fibro-elastosis is that the cardiac enlargement is predominantly left sided in contrast to other congenital abnormalities in which the enlargement is right sided. It is not suggested that left auricular enlargement only occurs in this disease but that its finding, taken in conjunction with the clinical picture, is a useful confirmatory sign. It is realized that backward displacement of the oesophagus may occur with general cardiac enlargement and also that in infants and children the left auricular impression on the barium-filled oesophagus in the right anterooblique position is more plainly seen than in adults
(Evans, 1952). In all our seven cases, however, there was convincing radiological evidence of left auricular enlargement.

Glycogen disease of the heart, which is a much rarer condition, may be impossible to distinguish in life from endocardial fibro-elastosis. It is likely that left auricular enlargement would also be found in glycogen disease although we have not been able to find any reports of this; this enlargement would, however, be part of a general cardiac enlargement not predominantly left sided. In other conditions causing cardiac enlargement in early life left auricular enlargement is not found. Some, like persistent truncus arteriosus and transposition of the great vessels, can be differentiated by the presence of persistent cyanosis while in cases of abnormal origin of a coronary artery an electrocardiogram will show the characteristic $T$ wave changes. Congenital mitral stenosis is usually, if not always, due to endocardial fibro-elastosis, the thickened endocardium distorting the valve; according to Gross (1941) endocardial thickening is found in $70 \%$ of cases of so-called foetal endocarditis. Mitral stenosis was found in two of our patients at necropsy (Cases 4 and 7). There was no correlation between its presence and the size of the left auricle as seen radiologically; in fact in Case 4 the left auricular enlargement was considered to be minimal (Table 1).

Blumberg and Lyon's statement (1952) that endocardial fibro-elastosis is one of the commonest types of fatal heart disease affecting infants has been borne out in our experience. The seven fatal cases described here have been seen in a period of 18 months. We have seen in addition three other patients, who are still alive, in whom the clinical picture is typical of this disease; radiographs show marked cardiac enlargement with demonstrable enlargement of the left auricle.

The recognition of the disease is important from a prognostic point of view and we have found the demonstration of left auricular enlargement to be a helpful sign in diagnosis.

\section{Summary}

Seven fatal cases of endocardial fibro-elastosis are briefly described. In all left auricular enlargement was demonstrated radiologically and this is considered to be a useful confirmatory sign in diagnosis.

We wish to thank Dr. J. Vernon Braithwaite for permission to record Case 7 , and Mr. E. V. Willmott for the photomicrographs.

\section{REFERENCES}

Blumberg. R. W. and Lyon. R. A. (1952). Amer. J. Dis. Child., 84 291.

Cosgrove, G. E. and Kaump, D. H. (1946). Amer. J. clin. Path.. 16, 322

Evans, W. (1952). Cardioscopv. London.

Gross, P. (1941). Arch. Path., Chicago, 31, 163. 